\title{
Short-term recognition memory for spatially isolated items ${ }^{1}$
}

\author{
ROBERT E. MORIN, DONALD V. DEROSA ${ }^{2}$ AND RONALD ULM ${ }^{3}$ \\ KENT STATE UNIVERSTTY
}

With from three to six digits presented prior to a recognition probe, the only evidence for a von Restorff effect existed in faster reaction times to probes of the isolated stimulus with sets of size 6.

Isolating an item from other items in a list improves retention of the isolated item (Wallace, 1965). Is this finding, namely, the von Restorff effect, observed in short-term recognition memory?

Of primary interest is the effect of isolation on the availability of an item as evidenced by a reaction time (RT) measure. One conception is that retrieval from short-term memory includes a search process wherein the test item is successively compared to elements in store. Making an item in the stored set distinctive could influence order of search. If the isolated item were promoted in the search order and search were to terminate with the occurrence of a match, then reactions to isolated stimuli should be faster than to nonisolated stimuli.

Method

The Ss were 12 male undergraduates who participated individually in six experimental sessions. Stimuli were single digit numerals (0-9) programmed by punched tape and presented on three Series 10,000 I.E.E. display cells mounted $3 \mathrm{ft}$ from S. Verbal responses keyed an electronic counter and RTs were printed by a digital recorder.

On each trial a positive set of $3,4,5$, or 6 different numerals was presented. Each numeral appeared for $.25 \mathrm{sec}$ and the interstimulus interval was .25 sec. On isolation trials one digit in the positive set appeared on the right cell of two horizontally adjacent cells. All other digits appeared on the left cell. In .25 sec after the termination of the final digit in the positive set, a probe digit with a red background appeared on a third cell centered and mounted immediately above the other two cells. The Ss were instructed to respondas rapidly as possible with the word "yes" if the probe was identical to any digit in the positive set, and by saying "no" otherwise. The intertrial interval was $1.5 \mathrm{sec}$. A rest of $1 \mathrm{~min}$ was given between lists and at the midpoint of lists for sets of size 5 and 6 .

On the initial experimental day, Ss were instructed and given 12 practice trials with sets of each size. Over the five test days, each $S$ was given 2080 trials divided into 40 lists. Lists for sets of size $3,4,5$, and 6 contained $24,40,60$, and 84 trials, respectively. Two lists of each size were presented on each day.

Trial types may be illustrated for sets of size 4 . For positive (yes) trials on which there was an isolated item, the item was one of 10 digits which appeared in one of four serial positions and one of four serial positions was probed, giving 160 trials. On positive control trials without an isolated item, the probe was one of 10 digits which appeared in one of four serial positions, giving 40 trials. In addition to the 200 positive trials there were 200 negative (no) trials for which each numeral appeared equally often as the probe digit.

Resulis

Isolation of a stimulus may affect reactions not only to that stimulus, but to nonisolated stimuli as well (Wallace, 1965). Consequently, the data for trials on which a nonisolated stimulus was probed are summarized separately for trials which included and trials which did not include an isolated stimulus. Figure 1 presents mean RT as a function of set size for the above two types of trials and also for trials on which the isolated stimulus was presented and tested. A fourth function summarizes reactions to negative probes.

Analyses of responses to positive probes showed that RT increased as a function of set size (linear $F=60.54$, $\mathrm{df}=1 / 11, \mathrm{p}<.01 ;$ quadratic $\mathrm{F}=10.03, \mathrm{df}=1 / 11, \mathrm{p}<.01$ ). Though overall differences in RT for the three types of positive trials graphed in Fig. 1 were significant ( $F=$ 10.77, df $=2 / 22, p<.01$ ), it is clear from a significant interaction between trial type and set size $(F=78.43$, $\mathrm{df}=2 / 22, \mathrm{p}<.01$ ) that any benefits which accrue to an isolated stimulus do so only with larger positive sets. Indeed, when tests of simple effects were performed for each set size, the only significant difference among

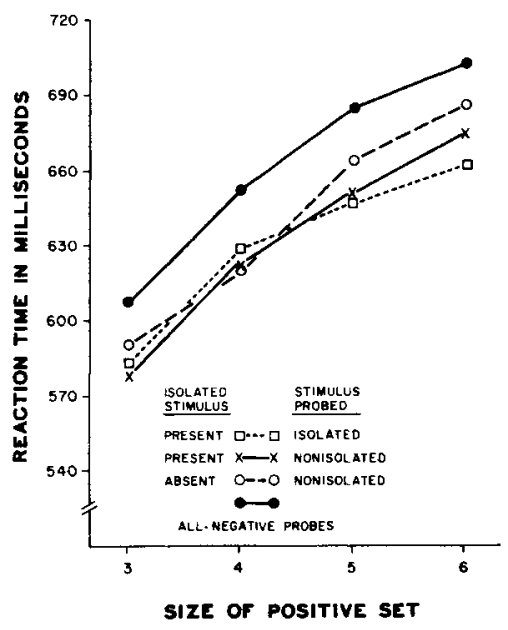

Fig. 1. Mean RT in msec as a function of positive set size for three types of trials. 
types of probes was found for sets of size $6(F=12.26$, $\mathrm{df}=2 / 22, \mathrm{p}<.01$ ). More analytical comparisons for sets of size 6 showed that, with an isolated stimulus present, reactions to isolated stimuli were significantly faster than to nonisolated stimuli $(F=7.87, \mathrm{df}=1 / 11, \mathrm{p}<.05)$. Furthermore, differences between the two types of nonisolated stimuli were significant $(\mathrm{F}=5.15, \mathrm{df}=1 / 11, \mathrm{p}<$ $.05)$ and favored trials with an isolated stimulus present.

Figure 2 presents RT plotted as a function of serial position for each set size. All functions showed marked recency effects. Significant interactions between trial type and serial position for all set sizes reflected, in part, greater primacy effects for trials with an isolated stimulus.

In Fig. 3 mean percent error is plotted against set size and serial position for the three trial types defined in the legend. There were no significant differences associated with the trial types. Recency effects, as evidenced by a decreasing linear trend, were large and highly significant for all set sizes. The primacy effects evidenced in Fig. 3 were consistent with significant quadratic components to the functions relating $\mathrm{RT}$ to serial position for sets of size 4,5 , and 6 .

\section{Discussion}

The only evidence for a von Restorff effect came from the RT measure and from trials on which six digits preceded the probe digit. Reactions to isolated stimuli averaged $24 \mathrm{msec}$ faster than the mean RT for

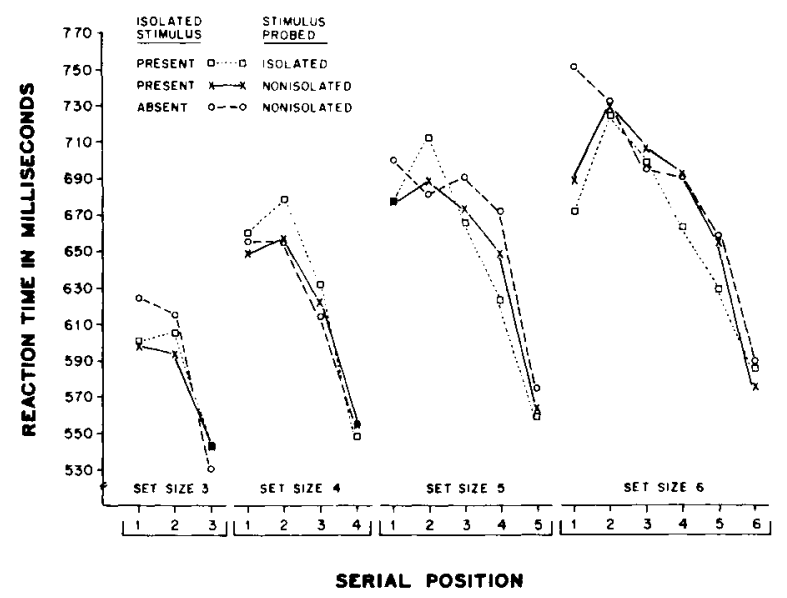

Fig. 2. Mean RT in msec as a function of positive set size and serial position.

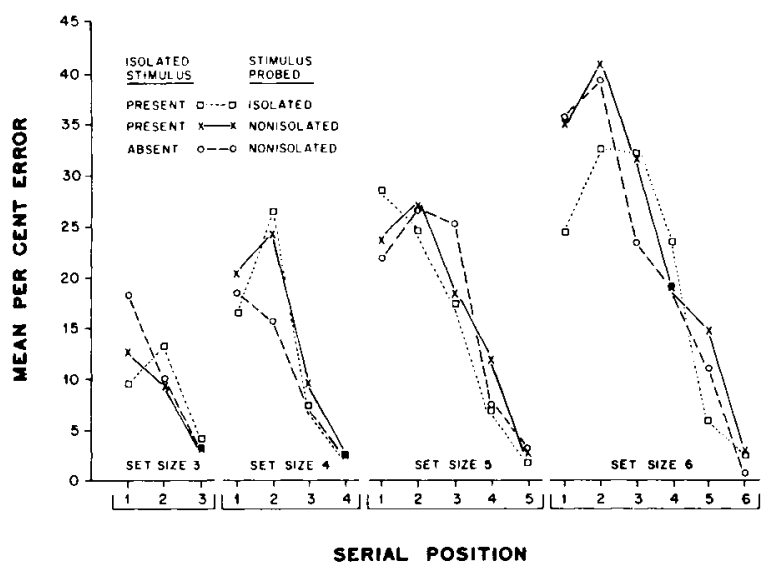

Fig. 3. Mean percent error as a function of positive set size and serial position.

control trials without an isolated stimulus. Though more pronounced effects might be observed with other types of isolation and/or with larger positive sets, the conclusion must be that spatial isolation does not make an item markedly more available. RT was clearly more dependent upon the serial position of a digit than upon the isolation variable.

Failure to find consistent evidence for a von Restorff effect is compatible with the serial exhaustive search model proposed by Sternberg (1966). Under the model, search does not terminate when a match occurs between the probe and an element of the positive set. Instead it continues until all possible comparisons have been made. Since the positive set is searched exhaustively on every trial, changes in search order brought about by isolating a stimulus should not be manifest in $R T$. On the other hand, marked differences in RT as a function of serial position are difficult to reconcile with an exhaustive search model.

\section{References}

STERNBERG, S. High-speed scanning in human memory. Science, $1966,153,652-654$.

WALLACE, W. P. Review of the historical, empirical, and theoretical status of the von Restorff phenomenon. Psychol. Bull., 1965, 63, $410-424$.

Note

1. Supported by National Science Foundation Grant GB-4343X.

2. Now at the University of Minnesota.

3. Now at Temple University. NSF Undergraduate Research Participant at Kent State University. 